\title{
Effect of Sodium Metabisulphite on Blood Metabolic Status of Wistar Rats
}

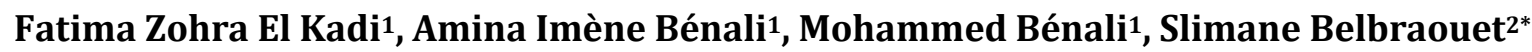 \\ ${ }^{1}$ Laboratoire de Biotoxicologie, Département de Biologie, Faculté des Sciences de la Nature et de la vie, \\ Université D Liabés, Sidi Bel Abbés, Algérie \\ ${ }^{2}$ École de Nutrition, Université de Moncton, Moncton, Canada \\ Email: elkadiftimazohra@yahoo.fr, benalimene@yahoo.fr, benalimo@yahoo.fr, \\ * slimane.belbraouet@umoncton.ca
}

Received 29 May 2014; revised 6 July 2014; accepted 16 July 2014

Copyright (C) 2014 by authors and Scientific Research Publishing Inc. This work is licensed under the Creative Commons Attribution International License (CC BY). http://creativecommons.org/licenses/by/4.0/

(c) (i) Open Access

\begin{abstract}
The objective of this work was to determine the sodium metabisulphite (NaMBS) subchronic toxicity used as a food additive in Algeria. Three groups of female Wistar rats were treated with $0.25 \%, 1 \%$ and $4 \%$ of NaMBS in their drinking water for 90 days. An immunization protocol was conducted during the experiment. Mortality, comportmental and weight modifications, and food and water consumption were recorded. At the end of the experiment, the control and experiment rats were killed, and their blood and organs were removed. Immunoglobulin levels were evaluated; biochemical and hematological parameters were investigated. Our results showed that the administration of NaMBS at $1 \%$ and $4 \%$ had significant effects on body weight, food and water consumed. There was an increase in biochemical parameters (calcium, urea, creatinine, uric acid, transaminases) and decrease immunoglobulin levels. The hematology revealed a decrease in red blood cells and hemoglobin, as well as leucocytosis. Physiological study showed enlarged spleen, kidney, liver and stomach. In light of our results, we can conclude that subchronic intake of NaMBS $1 \%$ and $4 \%$ seems to alter immune function, biochemical, hematological and physiological parameters in Wistar rats.
\end{abstract}

\section{Keywords}

Sodium Metabisulphite, Subchronic, Haematology, Biochemistry, Physiology, Wistar Rat

\section{Introduction}

Sulphites are substances naturally present in foods and in the body. They are also regulated food additives that

*Corresponding author.

How to cite this paper: El Kadi, F.Z., Bénali, A.I., Bénali, M. and Belbraouet, S. (2014) Effect of Sodium Metabisulphite on Blood Metabolic Status of Wistar Rats. Food and Nutrition Sciences, 5, 1529-1537. 
are used as preservatives to maintain the color and prolong the shelf life of food. They protect the preparations against enzymatic or non-enzymatic browning [1]. The European Union has classified them among the food preservatives [2]. Endogenous sulphites are normally generated in the human body by degradation of amino acids such as methionine and cysteine-sulphur. They can also be generated by polymorphonuclear neutrophils [3]. Several mammalian cells produce sulphites from $\mathrm{H}_{2} \mathrm{~S}$ [4]. Exogenous sources of sulphites include food, drinks, ambient air and pharmaceutical products [5].

There are several amino acid preparations used for parenteral nutrition that contain high levels of sulphites [6]. Although sulphites are very efficient, they are subject to restrictions of use due to their toxic effects. They have the ability to react with several molecules of biological importance such as DNA and may also be neurotoxic molecules by generating free radicals such as superoxide [7]. These radicals can also react with proteins and lipids [8]. Similarly, sulphites are additives and allergens to which the majority of asthmatics are sensitive [9].

Consumption of $0.25 \% \mathrm{Na}_{2} \mathrm{~S}_{2} \mathrm{O}_{5}$ supplemented food is equivalent $72 \mathrm{mg} / \mathrm{kg}$ of $\mathrm{SO}_{3}^{2-}$ intake daily. With this finding, Joint Expert Committee in the World Health Organization (WHO) has added 100 fold safety factor (by multiplying this number with 0.01 ) and has established acceptable daily intake (ADI) level of sulfites as 0.7 $\mathrm{mg} / \mathrm{kg} /$ body weight [10].

Thus, the aim of this study was to evaluate, in a sub-chronic study, the effects of ingestion of sodium metabisulphite (NaMBS) at levels of $0.25 \%, 1 \%$ and $4 \%$ on the biochemical, hematological and physiological parameters of Wistar rats.

\section{Material and Methods}

\subsection{Animals and Experimental Design}

Twenty four females Wistar rats (weighing $130.41 \pm 22.68 \mathrm{~g}$, 8 weeks old), were used in this study. During the entire experimental period, the animals were housed under standard conditions of temperature $\left(21^{\circ} \mathrm{C} \pm 2^{\circ} \mathrm{C}\right)$ and humidity (55\% $\pm 10 \%)$ with a 12-hour light/dark cycle and received a specific diet and water ad libitum according to the method of Lane-Peter and Pearson [11]. food and water were measured every day and body weight weekly. The animals were separated into four groups $(n=6)$ and received daily three different doses of NaMBS $(0.25 \%, 1 \%$, and $4 \%)$ in water for 12 weeks, the doses chosen are based on the value of acceptable daily intake ADI [12]. A 42-day immunization protocol was used [13].

At the end of the experiment (day 90), animals were fasted for approximately $16 \mathrm{~h}$ and were sacrificed by exsanguinations sunder urethane anesthesia. The sacrifice was done according to the guidelines of the regional Committee of Ethics of Animals, consistent with those agreed upon by the European Community on 24 November 1986 (86/609/EEC). Samples blood for hematological and clinical chemistry examinations were withdrawn from the abdominal aorta of rats, under conditions of food and water deprivation. Blood aliquots were put in different anticoagulants, according to the type of investigations. For the evaluation of hematological parameters, an aliquot of blood per animal was placed in ethylen-diamino-tetracetic-acid (K3-EDTA). For the evaluation of biochemical parameters, one aliquot of blood per animal was placed in a tube containing lithium-heparin and centrifuged at $4000 \times \mathrm{g}$ for 10 minutes at room temperature to obtain serum. The obtained serum is aliquoted in volumes of $50 \mu \mathrm{L}$ in Eppendorf tubes and frozen at $-20^{\circ} \mathrm{C}$. For the determination of immunochemical parameters blood samples were then collected to the nonanticoagulated tubes centrifuged and aliquoted for until analysis.

The organs (liver, spleen, thymus, kidney, and stomach) were carefully collected, rinsed with physiological saline $(0.9 \% \mathrm{NaCl})$, weighed, snap-frozen in liquid nitrogen, and stored at $-80^{\circ} \mathrm{C}$ until further analysis.

\subsection{Methods}

The chosen test substance was NaMBS- $\mathrm{Na}_{2} \mathrm{~S}_{2} \mathrm{O}_{5}^{-}$(Biochem International Chemopharma: 7681-57-4; Canada). The provider indicates a $95 \%$ degree of purity of the product. The substance presents itself as a very fine powder of white colour, pungent and very soluble in water.

The hematologic analyses were determined on the same day after the blood samples were taken from the rats,using automated Advia 60 CT (Bayer DC): white blood cells, red blood cells, hematocrit; haemoglobin was determined by the colorimetric method of Drabkin (cyanomethemoglobin) [14].

Biochemical assays were measured by spectrophotometer using commercial assay kits. Kidney functions, creatinine was measured by Jaffé. Colometric-kinetic method and urea was assayed by Berthelot. Enzymatic 
colorimetric method [15] using Spinreact kits (Spain) and recorded at spectrophotometer with wavelength 492 $\mathrm{nm}$ and $580 \mathrm{~nm}$, respectively. The level of uric acid was measured using enzymatic colorimetric test (PAPaminophenarose method) with lipid clearing factor (LCF) and recorded at spectrophotometer with wavelength 520 nm, using Human kits (Germany) [16] [17].

Total Cholesterol (TC) was estimated by enzymatic colorimetric assay (CHOD-PAP method) [18], triglycerides (TG) was determined by Glycerol Phosphate Oxidase/Peroxidase(GPO-PAP) method [19] [20] and recorded at spectrophotometer with wavelength $500 \mathrm{~nm}$, using Human kits (Germany).

Total protein (TP) was assayed by using the Biuret, colorimetric method and recorded at spectrophotometer with wavelength $540 \mathrm{~nm}$ [21], using Spinreact kits (Spain).

Liver functions, the activities of alanine aminotransferase (ALAT) and aspartate aminotransferase (ASAT) were adapted to determine in blood serum according to the kinetic method without activation by the pyridoxal phosphate [22], using Human kits (Germany).

Calcium value was determined by colorimetric method according to Stern \& Lewis [23], using Biomaghreb kits (France) and recorded at spectrophotometer with wavelength $570 \mathrm{~nm}$.

The rate of immunoglobulins is assayed by the reverse radial immunodiffusion technique of Mancini. The principle consists in depositing the antibody solution to be assayed in dug wells in a gel containing antigen. Antibodies diffuse into the gel and form rings of precipitation when the relative concentrations of the two elements are close to the equivalence point. The disc surface is proportional to the concentration of antibody [24]. For the optimization of this technique, we based our procedures on the protocols described by Mancini [25] and Vearman [26].

\subsection{Statistics}

The data is expressed as mean \pm standard deviation (X \pm SD). Statistical test one way ANOVA was applied to find significant difference between values of various parameters recorded for control and treated animals. $p<$ 0.05 was considered statistically significant.

\section{Results}

Regular monitoring of animals receiving water with $4 \%$ sulphites resulted in the following observations: diarrhea from the 2nd week; blood around the nose from the 4th week; and loss of hair from the 6th week. Anorexia and inhibition of growth were also observed.

The weight change of the control and experimental rats is illustrated in Figure 1. The values of weight gain in the control group and those receiving $0.25 \%$ and $1 \%$ of NaMBS were respectively $100.83 \pm 6.49 \mathrm{~g}, 115.33 \pm$ $7.55 \mathrm{~g}$ and $72.66 \pm 13.75 \mathrm{gr}$ Variations between these groups remain insignificant. In contrast, the rats treated with $4 \%$ of NaMBS showed very low weight gain and the inhibition of growth, and the difference was highly significant compared to the controls $(p<0.0001)$. At the highest doses of NaMBS food and water intakes were strongly diminished in the treated rats with $4 \%$ of NaMBS compared with controls during the 12 weeks of observation (Figure 2).

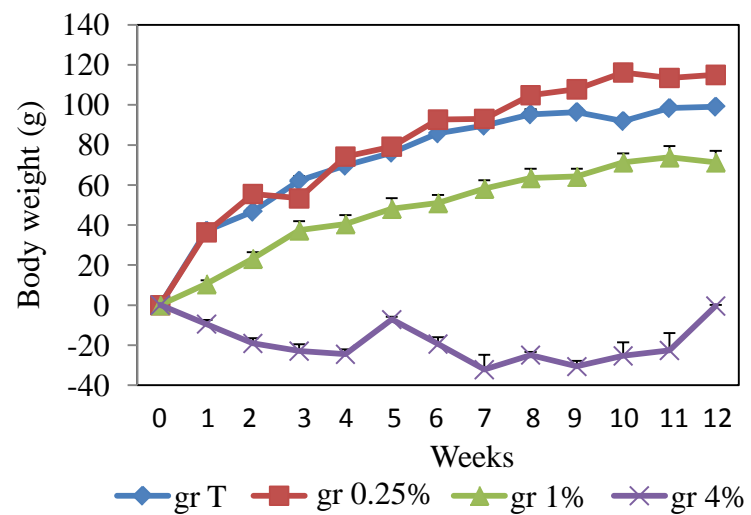

Figure 1. Body weight changes of control rats and rats treated with $0.25 \%, 1 \%$ and $4 \%$ of sodium metabisulfite daily for 12 weeks. Each value represents the mean \pm SD. 


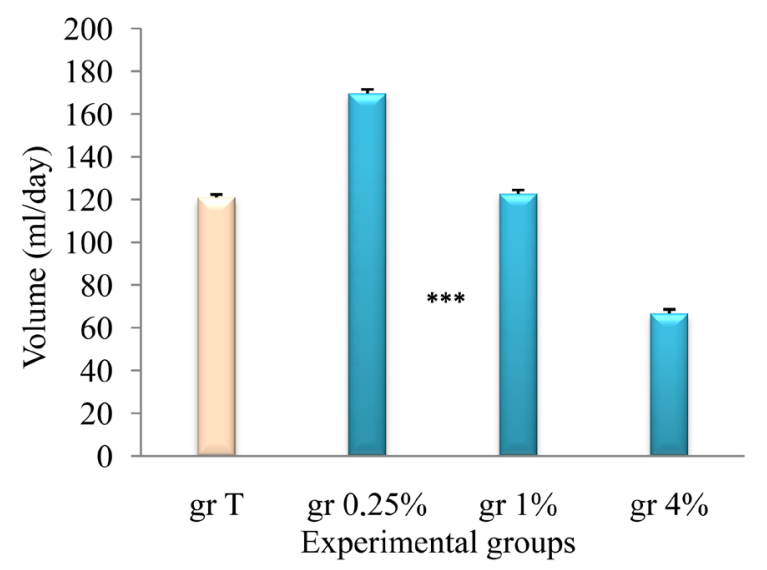

(a)

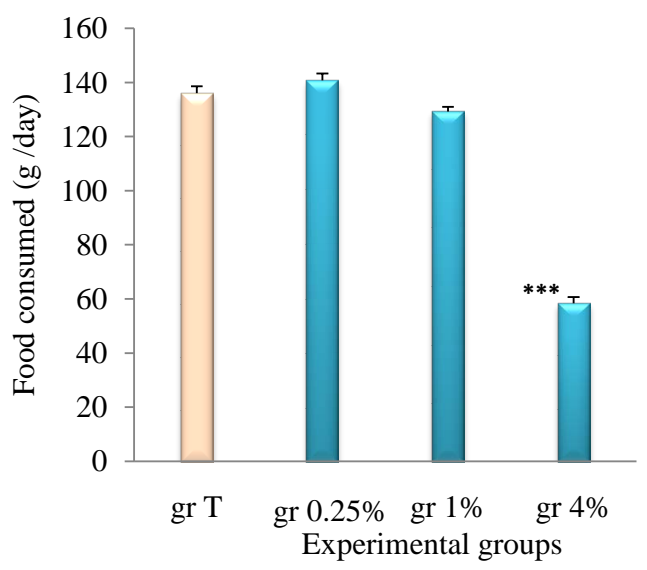

(b)

Figure 2. (a) Water intake (ml/day) of control rats and rats treated with $0.25 \%, 1 \%$ and $4 \%$ of sodium metabisulfite daily for 12 weeks. Each value represents the mean \pm SD; (b) Food consumption (g/day) of control rats andrats treated with $0.25 \%, 1 \%$ and $4 \%$ of sodium metabisulfite daily for 12 weeks. Each value represents the mean \pm SD. ${ }^{* * *}$ Statistically significant compared to control group; $p<0.001$.

According to the immunochemical test results, there was a decrease in the diameter of precipitates (immune complex antibody-antigen $\mathrm{Ab}-\mathrm{Ag}$ ) of the experimental groups receiving $1 \%$ and $4 \%$ of NaMBS compared with the control (Figure 3).

At the end of the experiment, various hematological parameters of treatment rats were measured and were compared with those of controls (Table 1). The results of the hematological study revealed a decrease in the number of red blood cells and the content of haemoglobin associated with leucocytosis in the group treated with $4 \%$ of NaMBS compared with the control group. The results of the different biochemical assays of the serum in the treatment groups compared to the control group are presented in Table 2. Rats treated with high doses of NaMBS (4\%) expressed a hypercalcemia and high rates of urea combined with hypercreatinemia and hyperuricemia. Increased serum transaminases were also found.

The assessment of the relative weights of taken organs of control and experimental rats treated with $1 \%$ showed an enlargement in spleen and liver. The group receiving $4 \%$ expressed a hypertrophy in spleen, liver, stomach, kidneys. However, no significant change was found in the weights of the thymus in the different experimental groups compared with the control group (Table 3).

\section{Discussion}

In this work, the effects in vivo of subchronic NaMBS consumption at doses of $0.25 \%, 1 \%$ and $4 \%$ were studied. The doses of sulfite administered in this project was determined in reference to previous studies designed to investigate the effects of high level of sulfite exposure via consuming certain foods and beverages containing sulfite [12] [27] [28]. In particular, there are several amino acid preparations utilized in total parenteral nutrition (TPN) solutions that contain large amounts of sulfites [6]. Sulfite toxicity is also considered possible with peritoneal dialysis fluids, some of which contain $\mathrm{Na}_{2} \mathrm{~S}_{2} \mathrm{O}_{5}$ in concentrations of $0.005 \%-0.012 \%$ [29]. Considering that many foods such as sausage, dried fruit, beer and wine contain $\mathrm{SO}_{2}^{3-}$, the daily level of normal $\mathrm{SO}_{2}^{3-}$ intake can easily be exceeded [30].

The results show that the effect of subchronic high-dose (4\%) of NaMBS administration in rats translates to clinical and behavioural changes (diarrhea, anorexia, hair loss). These neurobehavioural changes can be explained by the neurotoxic effect of sulphites, the toxicity of which is attributed to the release of sulphur and oxygen free radicals that can damage the central nervous system [8] [31] [32]. Reist et al. [33] showed that sulphite exerts toxic effects on neuronal cells grown directly or in combination with peroxynitrite. In addition, individuals suffering from a congenital disease caused by a deficiency of sulphite oxidase, a key enzyme in the metabolism of sulphites in the body that causes their oxidation to sulphate, develop severe neurological abnormalities with mental retardation, attenuated brain growth and early death [34].

The results obtained showed a significant decrease in food and water consumption associated with body 


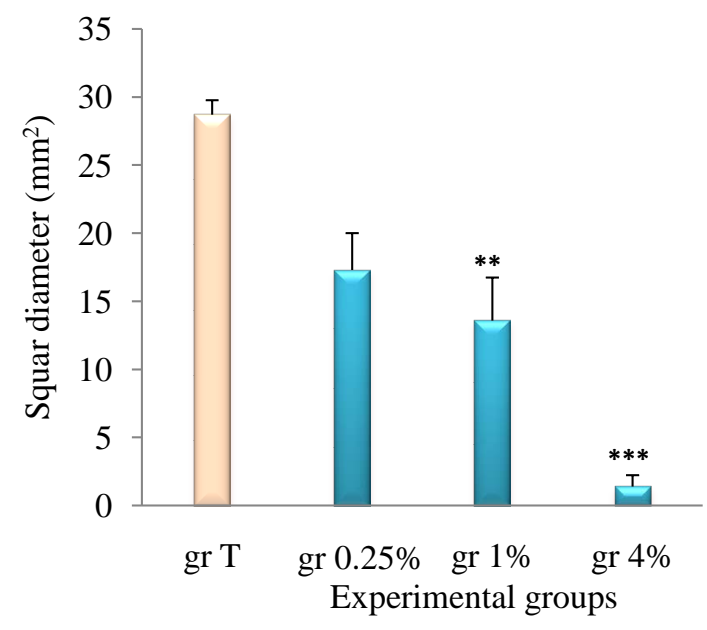

Figure 3. Square diameter $\left(\mathrm{D}^{2}\right)$ of the precipitate $\mathrm{Ab}-\mathrm{Ag}$ of controls rats andrats treated with $0.25 \%, 1 \%$ and $4 \%$ of sodium metabisulfite daily for 12 -weeks. Each value represents the mean $\pm \mathrm{SD}$. ${ }^{* *}$ Statistically significant compared to control group; $p<0.01 ;{ }^{* * *}$ Statistically significant compared to control group; $p<0.001$.

Table 1. Blood levels of some hematological parameters in controls rats and daily treated with $0.25 \%, 1 \%$, and $4 \%$ of sodium metabisulphite for 12 weeks.

\begin{tabular}{ccccc}
\hline Parameters & Controls & \multicolumn{3}{c}{ Experimental } \\
\cline { 3 - 5 } & & $0.25 \%$ & $1 \%$ & $4 \%$ \\
\hline Red blood cell $\left(10^{6} / \mathrm{mm}^{3}\right)$ & $7.17 \pm 0.14$ & $7.72 \pm 0.24$ & $6.56 \pm 0.44$ & $6.13 \pm 0.34^{*}$ \\
White blood cell $\left(10^{3} / \mathrm{mm}^{3}\right)$ & $3.13 \pm 0.42$ & $3.54 \pm 0.22$ & $2.5 \pm 0.11$ & $5.8 \pm 0.17^{* *}$ \\
Haemoglobin) $(\mathrm{g} / \mathrm{dl})$ & $13.98 \pm 0.25$ & $14.9 \pm 0.4$ & $12.7 \pm 0.43$ & $11.55 \pm 0.43^{*}$ \\
Hematocrit $(\%)$ & $40.11 \pm 1.17$ & $40.14 \pm 1.67$ & $40.85 \pm 1.83$ & $36.97 \pm 1.76$ \\
\hline
\end{tabular}

*Statistically significant compared to control group; $p<0.05$; ${ }^{* *}$ Statistically significant compared to control group; $p<0.01$; Results are expressed as Mean + SD standard deviation.

Table 2. Serum levels of biochemical parameters in controls rats and treated daily with $0.25 \%, 1 \%$, and $4 \%$ of sodium metabisulphite for 12 weeks.

\begin{tabular}{ccccc}
\hline & & \multicolumn{3}{c}{ Experimental } \\
Parameters & Controls & $0.25 \%$ & $1 \%$ & $4 \%$ \\
\cline { 3 - 4 } & & $65.6 \pm 2.16$ & $69.75 \pm 1.46$ & $67 \pm 1.73$ \\
T. protein $(\mathrm{gr} / \mathrm{L})$ & $2.26 \pm 0.12$ & $2.37 \pm 0.21$ & $2.21 \pm 0.08$ & $2.78 \pm 0.02^{*}$ \\
Calcium(mmol/L) & $11.77 \pm 0.02$ & $11.72 \pm 0.02$ & $10.92 \pm 0.01$ & $11.99 \pm 0.01^{*}$ \\
Urea $(\mathrm{mmol} / \mathrm{L})$ & $42.47 \pm 2.76$ & $42.92 \pm 6.9$ & $52.92 \pm 3.37$ & $57.7 \pm 2.93^{*}$ \\
Creatinine( $\mu \mathrm{mol} / \mathrm{L})$ & $160.05 \pm 28.07$ & $159.46 \pm 20.95$ & $61.89 \pm 23.8$ & $232.05 \pm 13.75^{*}$ \\
Uric acid $(\mu \mathrm{mol} / \mathrm{L})$ & $2.21 \pm 0.15$ & $2.16 \pm 0.17$ & $1.91 \pm 0.17$ & $1.83 \pm 0.04$ \\
T. cholesterol $(\mathrm{mmol} / \mathrm{L})$ & $0.98 \pm 0.29$ & $0.54 \pm 0.05$ & $0.76 \pm 0.08$ & $1.08 \pm 0.03$ \\
Triglycerides (mmol/L) & $68.66 \pm 4.27$ & $69.5 \pm 4.46$ & $131 \pm 22.69^{*}$ & $151 \pm 44.3^{*}$ \\
ASAT (IU/L) & $35 \pm 2.78$ & $41.6 \pm 10.63$ & $39.8 \pm 6.64$ & $30.8 \pm 0.38$ \\
ALAT (IU/L) & &
\end{tabular}

T: total; ASAT: aspartate aminotransferase; ALAT: alanine aminotransferase; Results are expressed as mean + SD standard deviation; ${ }^{*}$ Statistically significant compared to control group; $p<0.05$. 
Table 3. Relative organ weights (g) in controls rats and treated daily with $0.25 \%, 1 \%$, and $4 \%$ of sodium metabisulphite for 12 weeks.

\begin{tabular}{ccccc}
\hline & & \multicolumn{3}{c}{ Experimental } \\
Organ & Controls & $0.25 \%$ & $1 \%$ & $4 \%$ \\
\cline { 3 - 4 } Spleen & $0.37 \pm 0.01$ & $0.38 \pm 0.01$ & $0.45 \pm 0.02^{*}$ & $0.50 \pm 0.03^{* *}$ \\
Thymus & $0.12 \pm 0.01$ & $0.17 \pm 0.007$ & $0.13 \pm 0.01$ & $0.2 \pm 0.02$ \\
Stomach & $0.69 \pm 0.01$ & $0.76 \pm 0.09$ & $0.76 \pm 0.05$ & $1.48 \pm 0.09^{* *}$ \\
Liver & $3.13 \pm 0.15$ & $2.93 \pm 0.11$ & $3.85 \pm 0.12^{*}$ & $4.65 \pm 0.40^{* *}$ \\
Kidneys & $0.66 \pm 0.02$ & $0.7 \pm 0.02$ & $0.68 \pm 0.03$ & $0.98 \pm 0.0^{* *}$ \\
\hline
\end{tabular}

Results are expressed as mean $+\mathrm{SD}$ standard deviation. ${ }^{*}$ Statistically significant compared to control group; $p<0.05$. ${ }^{* *}$ Statistically significant compared to control group; $p<0.01$.

weight loss in the group receiving the highest dose (4\% of NaMBS). Sulphites have an unpleasant taste and smell so that their administration in drinking water might cause a decrease in the water consumption. In addition, the destruction of thiamine by sulphite is an important factor in the toxicological evaluation of this food additive. Thiamine destruction not only occurs when sulphite is added to the food, but also when it is present in the organism It thus appears as an antivitamin factor B1 [35]. This may explain the decrease in weight gain of animals treated with the highest dose.

These results are consistent with those of other studies, including those Till et al. [36], which showed that male and female rats fed high doses of NaMBS Joglur $(0 \%-8 \%)$ have reduced food consumption and weight growth. In a follow-up study [37], it was shown that a dose of $1.72 \%$ of NaMBS Joglur added to the diet causes a decrease in growth and feeding in male and female pigs during an experimental study of 12 months. Similarly, a study by inhalation was conducted by Miyata et al. [38]. Six rabbits exposed to dioxide of sulphur (186.2 $\mathrm{mg} / \mathrm{m}^{3}$ ) for 6 weeks. The main symptom was a decrease in growth.

The significant decrease in immunoglobulin in a manner inversely proportional to levels of administered of NaMBS Joglur explains the immunomodulatory effects of NaMBS. Several studies have been conducted to measure the impact of exposure to known concentrations of sulphites on the normal immunological mechanisms. The results show that sulphites in particular can influence the production of antibodies and agglutinins [39].

In order to assess the actual toxicity of NaMBS Joglur, different hematological and biochemical parameters were measured at the end of the experiment in treated rats and were compared to those of control rats. Our results show that a $4 \%$ dose causes a significant decrease in red blood cells and haemoglobin levels and a significant increase in white blood cells in the experimental rats compared to the controls. These results are in agreement with the work of Til [36], which showed the appearance of anaemia at $2 \%$ and a leucocytosis to $6 \%$ of NaMBS in Wistar rats. According to Gunnison [40], rats fed a diet containing 6\% of NaMBS Joglur for 21 days became severely anaemic. The results showed a significant increase in the concentration of serum calcium in the experimental group receiving $4 \%$ of NaMBS Joglur. Sulphites act on the excretion of the calcium through sulphate, to which they give rise in vivo [41].

Uric acid is the final product of the catabolism of purine [42]. The levels of uric acid in most mammals are lower than in humans due to the presence of uricase, a liver enzyme that degrades uric acid into allantoin [43]. Our results illustrate hyperuricemia exclusively in the group treated with the highest dose (4\%). The observed increase in serum levels of uric acid may be the result of reduced urinary excretion of the metabolite. Creatinine and urea are excellent markers of renal function, and their increase or decrease reflects a dysfunction of the renal function [44]. Transaminases are enzymes with important metabolic activity inside cells. Their increase in serum reflects cell damage, in particular at the hepatic level [45].

The results indicate that doses of $4 \%$ cause an increase in serum urea, creatinine and transaminases marking abnormal renal and hepatic function. Degradation of hepatic protein compounds may explain the increase in urea and serum creatinine in the treated rats, where proteins can be degraded into amino acids and then into urea and creatinine. Thus, these amino acids can be transformed by the action of the serum transaminase in carboxylic compounds such as pyruvic acid [46] which requires the high enzymatic activity of transaminases in rats treated with $4 \%$ of NaMBS. In this case, we may suggest that the high enzyme activity of the aspartate ami- 
notransferase (ASAT) and alanine aminotransferase(ALAT) is linked to the hepatotoxic effect of the xenobiotic, given that the liver is the principal organ of detoxification because it contains most of the enzymes of metabolism.

The assessment of the relative weight of the various bodies reveals that the doses of $4 \%$ cause an enlarged liver, spleen, kidney, stomach. The increase in the hepato-body and reno-body report has been highlighted indirectly by a disruption of the renal and hepatic enzyme system (increase serum in urea, creatinine, uric acid and transaminases in the animals treated with the highest dose). The increase of thespleen weight is the result ofan increased extra-medullary splenic hematopoietic activity and increased leucocyte counts. This result is fully consistent with the work of Til et al. [36], which showed the presence of splenomegaly in rats receiving doses of $4 \%$ or more of NaMBS. In a follow-up study, they showed an enlarged liver, kidney and heart of pigs treated with $0.83 \%$ and $1.72 \%$ of NaMBS [36].

\section{Conclusions}

Females Wistar rats oral exposed to NaMBS, at levels up to $4 \%$ in the water, during 12 weeks, shown alterations in immunochemical, biochemical (calcium, uric acid, urea, creatinine, transaminases), hematological (hemoglobin, red blood cell, and white blood cells) parameters in relation to the control group. Similarly, the oral administration of $4 \%$ of NaMBS for 12 weeks causes hypertrophy of kidneys, liver, spleen and stomach. These results lead to considerations of the development of other research focused on the determination of biomarkers of oxidative stress induced by sulphite (glutathione, superoxide dismutase, cytochrome P450, catalase, substances reacting with thiobarbituric acid, malondialdehyde, vitamins, etc.) for a better analysis of potential toxic effects of this synthetic preservative. Our recommendations relate to the control of their unauthorized presence in foods or their presence at unauthorized rates:

- remove or replace their use in foodstuffs for which their use is not required;

- reduce the use of these additives when technologically possible;

- increase the legibility and visibility of labelling (this is particularly useful for asthmatics).

In addition, sulphites do not meet the current demand for consumer which is turning more and more towards a natural diet free from synthetic additives. Natural additives such as vitamin C, citric acid and tocopherols can also be used as alternative preservatives to be able to propose products to consumers without hazards, natural, good for health and practices.

\section{References}

[1] Taylor, S.L., Bush, R.K. and Nordlee, J.A. (2008) Sulfites. In: Metcalfe, D.D., Sampson, H.A. and Simon, R.A., Eds., Food Allergy: Adverse Reactions to Foods and Food Additives, 4th Edition, Blackwell Publishing, 29, 353-368.

[2] Denil, M. and Lannoye, P. (2004) Guide of Food Additives-Precautions to Take. 2nd Edition, Frison-Roche, Paris, $1-164$.

[3] Mitsuhashi, H., Nojima, Y., Tanaka, T., Ueki, K., Maezawa, A. and Yano, S. (1998) Sulfite Is Released by Human Neutrophils in Response to Stimulation with Lipopolysaccharide. Journal of Leukocyte Biology, 64, 595-599.

[4] Mitsuhashi, H., Yamashita, S., Ikeuchi, H., Kuroiwa, T., Kaneko, Y. and Hiromura, K. (2005) Oxidative Stress-Dependent Conversion of Hydrogen Sulfide to Sulfite by Activated Neutrophils. Shock, 24, 529-534. http://dx.doi.org/10.1097/01.shk.0000183393.83272.de

[5] Lester, M.R. (1995) Sulfite Sensitivity: Significance in Human Health. The Journal of the American College of Nutrition, 14, 229-232. http://dx.doi.org/10.1080/07315724.1995.10718500

[6] Lakamp, J.E. and Dobesh, P.P. (2000) Propofol and Too Much Sulfite? Chest, 118, 277. http://dx.doi.org/10.1378/chest.118.1.277-a

[7] Ozturk, O.H., Kucukatay, V., Yonden, Z., Agar, A., Bagci, H. and Delibas, N. (2006) Expressions of N-Methyl-D-Aspartate Receptors NR2A and NR2B Subunit Proteins in Normal and Sulfite-Oxidase Deficient Rat's Hippocampus: Effect of Exogenous Sulfite Ingestion. Archives of Toxicology, 80, 671-679. http://dx.doi.org/10.1007/s00204-006-0125-X

[8] Zhang, X., Vincent, A.S., Halliwell, B. and Wong, K.P. (2004) A Mechanism of Sulfite Neurotoxicity: Direct Inhibition of Glutamate Dehydrogenase. Journal of Biological Chemistry, 279, 43035-43045.

[9] Vally, H. and Thompson, P.J. (2001) Role of Sulphite in Wine Induced Asthma: Single Dose and Cumulative Dose Studies. Thorax, 56, 763-769. http://dx.doi.org/10.1136/thorax.56.10.763 
[10] Nair, B. and Elmore, A.R. (2003) Cosmetic Ingredients Review Expert Panel. Final Report on the Safety Assessment of Sodium Sulfite, Potassium Sulfite, Ammonium Sulfite, Sodium Bisulfite, Ammonium Bisulfite, Sodium Metabisulfite and Potassium Metabisulfite. International Journal of Toxicology, 22, 63-88. http://dx.doi.org/10.1080/10915810305077X

[11] Lane Peter, W. and Person, A.E.G. (1971) Dietary Requirements in the Laboratory: Animal Principles and Practice. Academic Press, London and New York, 142.

[12] Hui, J.Y., Beery, J.T., Higley, N.A. and Taylor, S.L. (1989) Comparative Subchronic Oral Toxicity of Sulphite and Acetaldehyde Hydroxysulphonate in Rats. Food and Chemical Toxicology, 27, 349-359. http://dx.doi.org/10.1016/0278-6915(89)90140-3

[13] Duddukuri, G.R., Vasudeva, R.Y., Rao, D.N. and Athota, R.R. (2001) Immunomodulation of Ovalbumin-Specific IgG and Other Classes of Antibody Response by Honey in Mice. Indian Journal of Clinical Biochimistry, 16, 89-94. http://dx.doi.org/10.1007/BF02867574

[14] Drabkin, D.S. and Austin, J.H. (1932) Spectophotometric Constants for Common Hemoglobin Derivatives in Human, Dog, and Rabbit Blood. Journal of Biological Chemistry, 98, 719-733.

[15] Young, D.S. (2001) Effects of Disease on Clinical Lab Tests. 4th Edition, AACC, Washington DC.

[16] Barham, D. and Trinder, P. (1972) An Improved Colour Reagent for the Determination of Blood Glucose by the Oxidase System. Analyst, 97, 142-145. http://dx.doi.org/10.1039/an9729700142

[17] Fossati, P., Prencipe, L. and Berti, G. (1980) Use of 3,5-Dichloro-2-Hydroxybenzenesulfonic Acid/4-Aminophenazone Chromogenic System in Direct Enzymic Assay of Uric Acid in Serum and Urine. Clinical Chemistry, 26, $227-231$.

[18] Meiattini, F., Prencipe, L., Bardelli, F., Giannini, G. and Tarli, P. (1978) The 4-Hydroxybenzoate/4-Aminophenazone Chromogenic System Used in the Enzymic Determination of Serum Cholesterol. Clinical Chemistry, 24, 2161-2165.

[19] Bucolo, G. and David, H. (1973) Quantitative Determination of Serum Triglycerides by Use of Enzymes. Clinical Chemistry, 19, 476-482.

[20] Fossati, P. and Prencipe, L. (1982) Serum Triglycerides Determined Colorimetrically with an Enzyme that Produces Hydrogen Peroxide. Clinical Chemistry, 28, 2077-2080.

[21] Burtis, C.A. and Ashwood, E.R. (1999) Tietz Textbook of Clinical Chemistry. 3rd Edition, W. B. Saunders, Philadelphia.

[22] Bergmeyer, H.U. (1980) IFCC Methods for Measurement of Catalytic Concentrations of Enzymes. Clinica Chimica Acta, 105, 147-154. http://dx.doi.org/10.1016/0009-8981(80)90105-9

[23] Stern, J. and Lewis, W.H.P. (1957) The Colorimetric Estimation of Calcium Inserum with o-Cresolphthalein Complexone. Clinica Chimica Acta, 2, 576-580. http://dx.doi.org/10.1016/0009-8981(57)90063-3

[24] Male, D. and Fonteneau, P. (2005) Immunology, Memory-Aid Illustrated. 4th Edition, De Boeck, Paris, 132.

[25] Mancini, G., Carbonara, A.O. and Heremans, J.F. (1965) Immunochemical Quantitation of Antigens by Single Radial Immunodiffusion. Pergamon Press, Immunochemistry, 2, 235-254. http://dx.doi.org/10.1016/0019-2791(65)90004-2

[26] Vaerman, J.P., Lebacq-Verhayden, A.M., Scolari, L. and Heremans, J.F. (1968) Further Studies on Single Radial Immunodiffusion-II the Reversed System: Diffusion of Antibodies in Antigen Containing Gels. Immunochemistry, 6, $287-$ 293. http://dx.doi.org/10.1016/0019-2791(69)90165-7

[27] Derin, N., Akpinar, D., Yargicoglu, P., Agar, A. and Aslan, M. (2009) Effect of Alpha-Lipoic Acid on Visual Evoked Potentials in Rats Exposed to Sulfite. Neurotoxicology and Teratology, 31, 34-39. http://dx.doi.org/10.1016/j.ntt.2008.08.002

[28] Ercan, S., Ozturk, N., Celik-Ozenci, C., Gungor, N.E. and Yargicoglu, P. (2010) Sodium Metabisulfite Induces Lipid Peroxidation and Apoptosis in Rat Gastric Tissue. Toxicology and Industrial Health, 26, 425-431. http://dx.doi.org/10.1177/0748233710369665

[29] MacPherson, R.D. (2001) Pharmaceutics for the Anaesthetist. Anaesthesia, 56, 965-979. http://dx.doi.org/10.1046/j.1365-2044.2001.02216.x

[30] Derin, N., Yargicoglu, P., Aslan, M., Elmas, O., Agar, A. and Aiciguzel, Y. (2006) The Effect of Sulfite and Chronic Restraint Stress on Brain Lipid Peroxidation and Antioxidant Enzyme Activities. Toxicology and Industrial Health, 22, 233-240. http://dx.doi.org/10.1191/0748233706th264oa

[31] Meng, Z. and Liu, Y. (2007) Cell Morphological Ultrastructural Changes in Various Organs from Mice Exposed by Inhalation to Sulfur Dioxide. Inhalation Toxicology, 19, 543-551. http://dx.doi.org/10.1080/08958370701271373

[32] Li, J. and Meng, Z. (2009) The Role of Sulfur Dioxide as an Endogenous Gaseous Vasoactive Factor in Synergy with Nitric Oxide. Nitric Oxide, 20, 166-174. http://dx.doi.org/10.1016/j.niox.2008.12.003

[33] Reist, M., Marshall, K.A., Jenner, P. and Halliwell, B. (1998) Toxic Effects of Sulphite in Combination with Peroxyni- 
trite on Neuronal Cells. Journal of Neurochemistry, 71, 2431-2438. http://dx.doi.org/10.1046/j.1471-4159.1998.71062431.x

[34] Johnson, J.L. (2003) Prenatal Diagnosis of Molybdenum Cofactor Deficiency and Isolated Sulfite Oxidase Deficiency. Prenatal Diagnosis, 23, 6-8. http://dx.doi.org/10.1002/pd.505

[35] FAO/WHO Expert Committee of Food Additives Sulfur Dioxide (2007). http://www.inchem.org/documents/jecfa/jeceval/jec_2215.htm

[36] Til, H.P., Feron, V.J. and De Groot, A.P. (1972) Toxicity of Sulfite. I. Long Term Feeding and Multigeneration Studies in Rats. Food and Cosmetics Toxicology, 10, 291-310. http://dx.doi.org/10.1016/S0015-6264(72)80250-5

[37] Til, H.P., Feron, V.J. and De Groot, A.P. (1972) The Toxicity of Sulphite. II. Short- and Long-Term Feeding Studies in Pigs. Food and Cosmetics Toxicology, 10, 463-473. http://dx.doi.org/10.1016/S0015-6264(72)80081-6

[38] Miyata, T., Ishii, T., Sugiyama, N., Okano, Y., Nishi, N., Takahama, K., Ogasawara, S., Oda, Y., Yokoyama, K., Murata, Y., et al. (1990) Effect of N-Acetylneuraminic Acid on Respiratory Tract Secretion and Inflammation in the Bronchitic Rabbit. Archives Internationales de Pharmacodynamie et de Thérapie, 304, 277-289.

[39] Chamulitrat, W. (1999) Activation of the Superoxide-Generating NADPH Oxidase of Intestinal Lymphocytes Produces Highly Reactive Free Radicals from Sulfite. Free Radical Biology and Medicine, 27, 411-421. http://dx.doi.org/10.1016/S0891-5849(99)00088-X

[40] Gunnison, A.F. (1981) Sulfite Toxicity: A Critical Review of in Vitro and in Vivo Data. Food and Cosmetics Toxicology, 19, 667-682. http://dx.doi.org/10.1016/0015-6264(81)90519-8

[41] Hugot, D., Causeret, J. and Leclerc, J. (1965) Effect of Ingestion of Sulfites on the Excretion of Calcium by Rats. Annales de Biologie Animale Biochimie Biophysique, 5, 53-59. http://dx.doi.org/10.1051/rnd:19650104

[42] Regoli, F. and Winston, G.W. (1999) Quantification of Total Oxidant Scavenging Capacity of Antioxidants for Peroxynitrite, Peroxyl Radicals, and Hydroxyl Radicals. Toxicology and Applied Pharmacology, 156, 96-105. http://dx.doi.org/10.1006/taap.1999.8637

[43] Wu, X.W., Muzny, D.M., Lee, C.C. and Caskey, C.T. (1992) Two Independent Mutational Events in the Loss of Urate Oxidase during Hominoid Evolution. Journal of Molecular Evolution, 34, 78-84. http://dx.doi.org/10.1007/BF00163854

[44] Sirwal, I.A., Banday, K.A., Reshi, A.R., Bhat, M.A. and Wani, M.M. (2004) Estimation of Glomerular Filtration Rate (GFR). JK Science, 6, 121-123.

[45] Kew, M.C. (2000) Serum Aminotransferase Concentration as Evidence of Hepatocellular Damage. Lancet, 355, 591592. http://dx.doi.org/10.1016/S0140-6736(99)00219-6

[46] Bergmeyer, H. (1980) Dietary Nitrate in Man: Friend or Foe? Clinica Chimica Acta, 105, 147-152. 
Scientific Research Publishing (SCIRP) is one of the largest Open Access journal publishers. It is currently publishing more than 200 open access, online, peer-reviewed journals covering a wide range of academic disciplines. SCIRP serves the worldwide academic communities and contributes to the progress and application of science with its publication.

Other selected journals from SCIRP are listed as below. Submit your manuscript to us via either submit@scirp.org or Online Submission Portal.
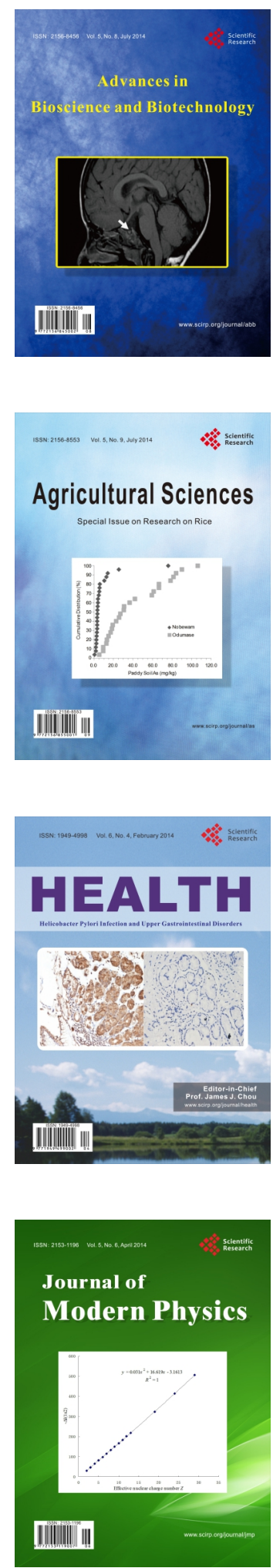
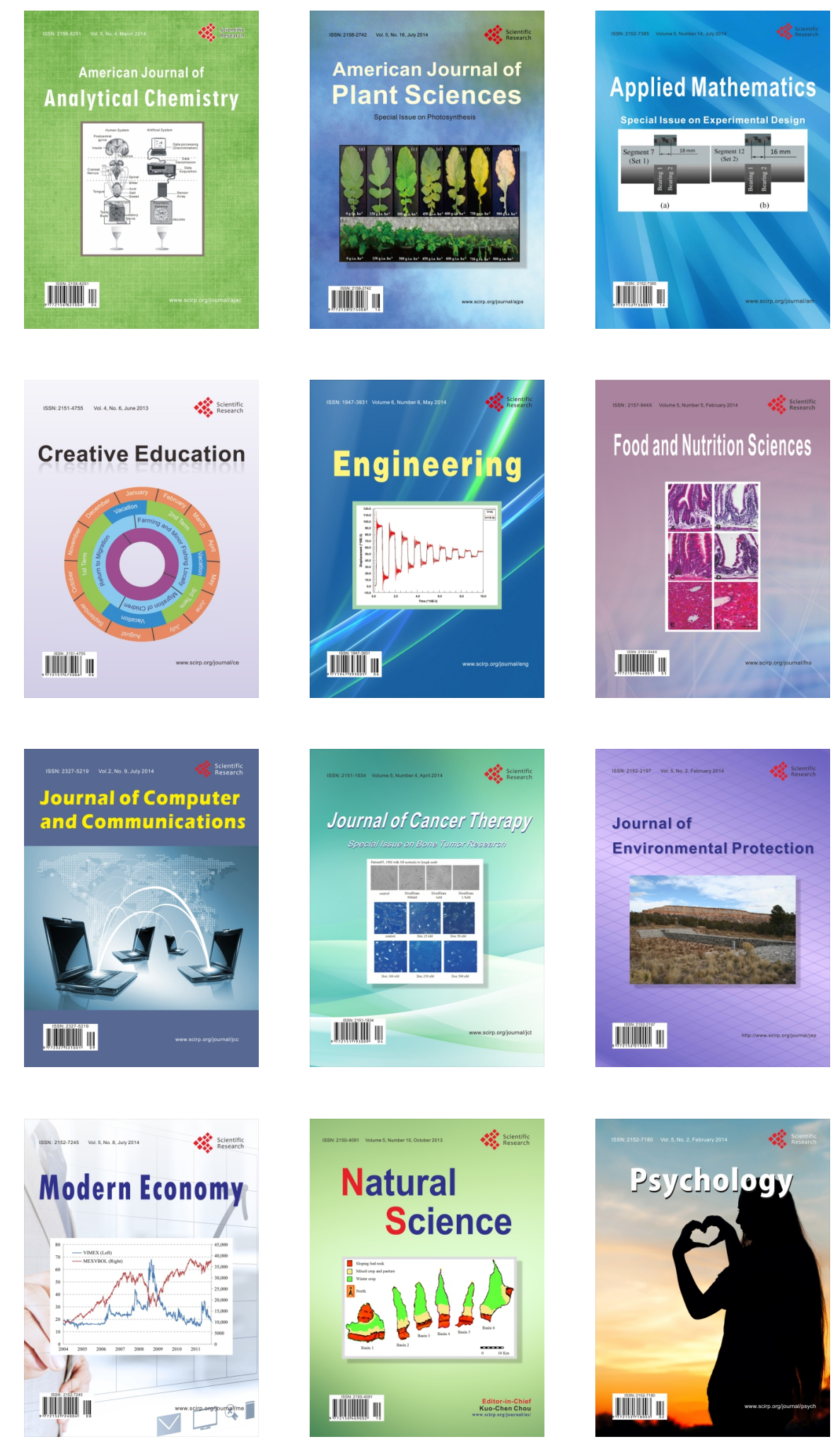